САПРЫКА Виктор Александрович - доктор социологических наук, заведующий кафедрой социальных технологий и государственной службы Белгородского государственного национального исследовательского университета (308015, Россия, г. Белгород, ул. Победы, 85; sapryka@bsu.edu.ru)

КУЛАКОВА Наталья Игоревна - аспирант кафедры социальных технологий и государственной службы Белгородского государственного национального исследовательского университета (308015, Россия, г. Белгород, ул. Победы, 85)

СОЛОХА Валерий Викторович - соискатель кафедры социальных технологий и государственной службы Белгородского государственного национального исследовательского университета (308015, Россия, г. Белгород, ул. Победы, 85)

ОЛЕЙНИК Светлана Анатольевна - соискатель кафедры социальных технологий и государственной службы Белгородского государственного национального исследовательского университета (308015, Россия, г. Белгород, ул. Победы, 85)

\title{
СОЦИОКУЛЬТУРНЫЕ РИСКИ И УГРОЗЫ ДЛЯ РАЗВИТИЯ ПРИГРАНИЧНЫХ РЕГИОНОВ
}

\begin{abstract}
Аннотация. В статье рассматриваются особенности развития приграничных регионов. Выделены социокультурные риски и угрозы, возникающие на территории приграничья. В исследовании определяются тенденции для прогнозирования возможных векторов развития приграничных регионов и принятия управленческих решений. Авторы рассматривают региональные факторы, выражающие культурно-цивилизационные особенности приграничных стран и современного мирового развития. Статья сфокусирована на социокультурных трансформациях в российско-украинском, российско-белорусском и российско-европейском приграничье, которые определяют особенности приграничного развития регионов.

Ключевые слова: социокультурные риски, угрозы, развитие, культурно-цивилизационные особенности, приграничные регионы
\end{abstract}

B настоящее время развитие приграничных регионов напрямую зависит от геополитических процессов и социокультурных трансформаций. В большом числе и разнообразии новых социальных вызовов особенно выделяются риски и угрозы в социокультурной сфере, оказывающие значительное влияние на все другие сферы жизнедеятельности общества [Туркулец, Туркулец, Листопадова 2021: 19]. Население приграничных территорий проявляет высокую восприимчивость к этим процессам, а также к нерешенным проблемам, связанным как с появлением новых границ на постсоветском пространстве, так и с возникающими социокультурными особенностями развития приграничья. Особенности социокультурной трансформации приграничных форм взаимодействия в значительной степени определяются статусом границы и - в едва ли не большей степени - восприятием границы и приграничья массовым и элитарным сознанием.

В условиях глобализации социокультурное пространство является открытой системой, куда проникают как положительные, так и отрицательные элементы других культур, которые придают социокультурному пространству неравновесный и противоречивый характер [Солихджонов, Джонназарова 2013: 189]. Процесс трансформации социокультурного пространства приграничных регионов необходимо рассматривать с позиций неопределенности и стохастичности результата, а также девальвации культурных образцов в силу нарастания угроз и рисков.

Современные глобальные трансформации, затрагивающие политическую, экономическую и культурную сферы социума, нарушают привычные формы жизнедеятельности локальных социальных структур [Игошева 2019: 25]. В 
приграничных социумах не только изменяется ценностная иерархия, направленная на традиционное сотрудничество, но и возникает реальная угроза для приграничного взаимодействия. С одной стороны, оценка потенциала приграничного сотрудничества приводит к выводу о его необходимости для эффективного взаимодействия регионов граничащих государств. Об этом свидетельствует наличие таких компонентов, как территориальная, родственная, деятельностная общность, инерция общей культурно-цивилизационной идентичности, языковая, коммуникативная, эмоциональная общность.

Перечисленные общности можно отнести к объективным элементам социокультурной интеграции, которые направлены на сохранение традиционного приграничного социума и дальнейшее сотрудничество. В тоже время стоит отметить и наиболее значительные барьеры, связанные с формированием новых культурно-цивилизационных идентичностей в приграничных регионах постсоветских стран, которые приводят к нарастанию отчужденности, снижению взаимного интереса, ухудшению взаимопонимания. Приграничные регионы как буферные зоны, находящиеся между экономическими, политическими и культурными границами, имеют свои особенности, актуальные для изучения в контексте модернизации российского общества, необходимости разработки дифференцированного подхода в регулировании регионального развития [Омельченко, Максимова, Ноянзина 2021: 13]. Вместе с тем социокультурные риски и угрозы для развития приграничных регионов не имеют четкого научного представления и зачастую не учитываются ни в стратегиях территориального развития, ни в стратегических планах, ни в концепциях национальной безопасности [Нарыков, Скворцов 2020: 27-28]. Этнокультурная безопасность многонациональной России и ее регионов должна выражаться в стремлении сохранить многообразие, поликультурность, многоязычие социального мира, основой которого является многонациональная мозаичная социальная действительность в понимании роли этнокультурной и национальной самоидентификации каждого конкретного человека в рамках собственной национальной культуры [Удаев 2018: 156].

Целью данной статьи является выделение социокультурных рисков и угроз для развития приграничных регионов, а также определение управленческих решений для их снижения. Социокультурная среда приграничных регионов в настоящее время характеризуется противоречивостью, предопределяющей неоднозначное восприятие трансформации форм взаимодействия. Несмотря на то что в силу инерции сознания большая часть жителей постсоветского приграничья потенциально ориентирована на формы сотрудничества, социологические исследования показывают, что население не всегда понимает перспективы сотрудничества, мало связывает с ними положительные ожидания в краткосрочной перспективе. Социокультурная специфика трансформации форм приграничного взаимодействия выражается в асинхронности культурноцивилизационного развития приграничных регионов, которая проявляется в стремительном переходе от традиционного сотрудничества к взаимодействию, а иногда и отчуждению.

Определение социокультурных рисков и угроз необходимо для развития приграничных регионов и приграничного сотрудничества. Реализация приграничного сотрудничества во многом зависит от ряда внешних и прежде всего социокультурных факторов, которые определяют возможности и предпосылки дальнейшей интеграции или дезинтеграции когда-то общего социального пространства. Реализации приграничного сотрудничества препятствует множество факторов, таких как информационное противостояние, политическая напряженность, усложнение геополитической ситуации, давление радикальных 
групп населения, распространение различных фобий и т.д. Противоположный вариант заключается в том, что складываются благоприятные внешние обстоятельства, которые выступают пусковым механизмом для приведения в действие социокультурного потенциала приграничных территорий, который превращает их в территорию добрососедства и сотрудничества.

Исследование, которое было проведено в 2021 г. на территории российскобелорусского, российско-украинского и росийско-европейского приграничья, позволило выявить, что основной социокультурной угрозой западного порубежья является снижение общего уровня нравственности и морали в бывших регионах $\mathrm{CCCP}^{1}$.

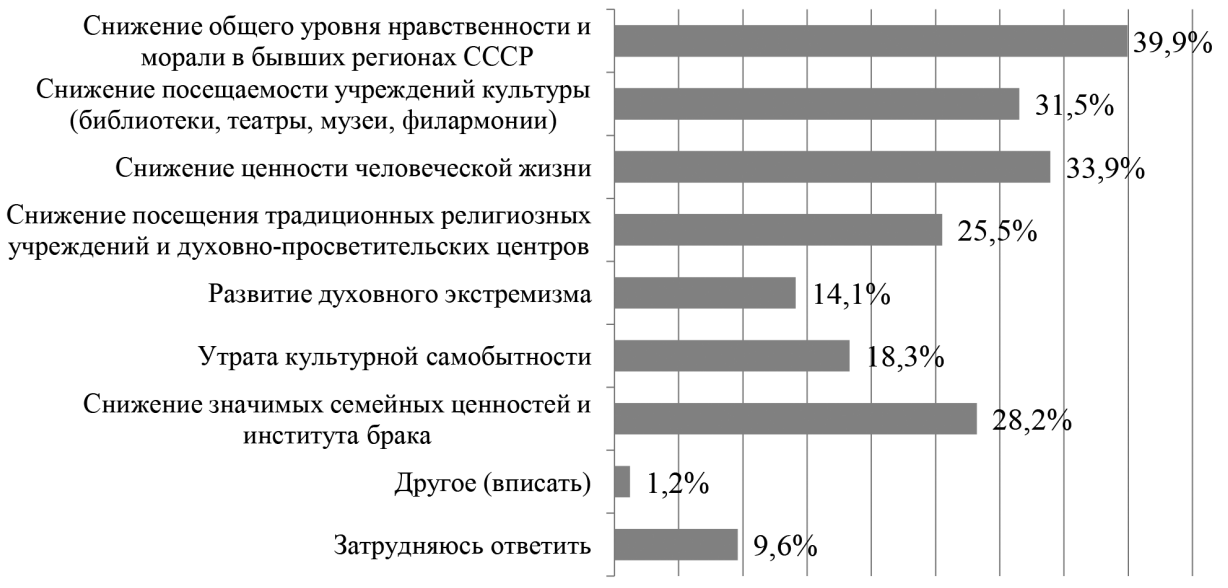

Рисунок 1. Распределение ответов на вопрос: «В чем, по Вашему мнению, выражается изменение в культурном поведении граждан приграничных регионов?» (Белгородская обл.)

Сравнение результатов проведенного исследования позволило выявить региональные различия в мнениях населения относительно ключевых негативных изменений в культурном поведении жителей приграничных регионов. Так, например, в Белгородской обл. респонденты подчеркивали снижение общего уровня морали, которым характеризуется постсоветский период истории современной России (39,9\%). Также было отмечено снижение ценности человеческой жизни $(33,9 \%)$. В качестве еще одного негативного проявления социокультурных изменений жители Белгородской обл. выделили снижение посещаемости учреждений культуры различного типа.

Вместе с тем такие ответы, как «утрата культурной самобытности» и «развитие духовного экстремизма», респонденты отмечали наиболее редко. По нашему мнению, это может быть связано с тем, что российско-украинское приграничье, частью которого является Белгородская обл., длительное время представляло собой пространство активной транскультурной коммуникации и добрососедства. И лишь в последнее время произошло увеличение числа социокультурных угроз, формируемых границей.

Схожее распределение ответов респондентов зафиксировано и в Смоленской обл. Однако здесь респонденты существенно чаще $(24,3 \%)$ отмечали утрату

1 Исследование проведено в феврале-июне 2021 г. Использовалась квотная половозрастная выборка. Выборочная совокупность составила 1000 чел. 
Снижение общего уровня нравственности и морали в бывших регионах СССР

Снижение посещаемости учреждений культуры (библиотеки, театры, музеи, филармонии)

Снижение ценности человеческой жизни

Снижение посещения традиционных религиозных учреждений и духовно-просветительских центров

Развитие духовного экстремизма

Утрата культурной самобытности

Снижение значимых семейных ценностей и института брака

Другое (вписать)

Затрудняюсь ответить

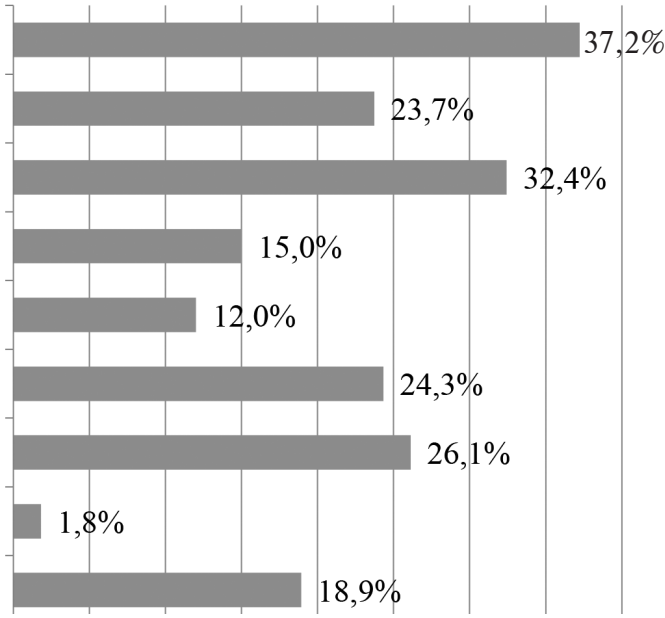

Рисунок 2. Распределение ответов на вопрос: «В чем, по Вашему мнению, выражается изменение в культурном поведении граждан приграничных регионов?» (Смоленская обл.)

культурной самобытности как одну из характеристик культурного поведения жителей приграничного региона.
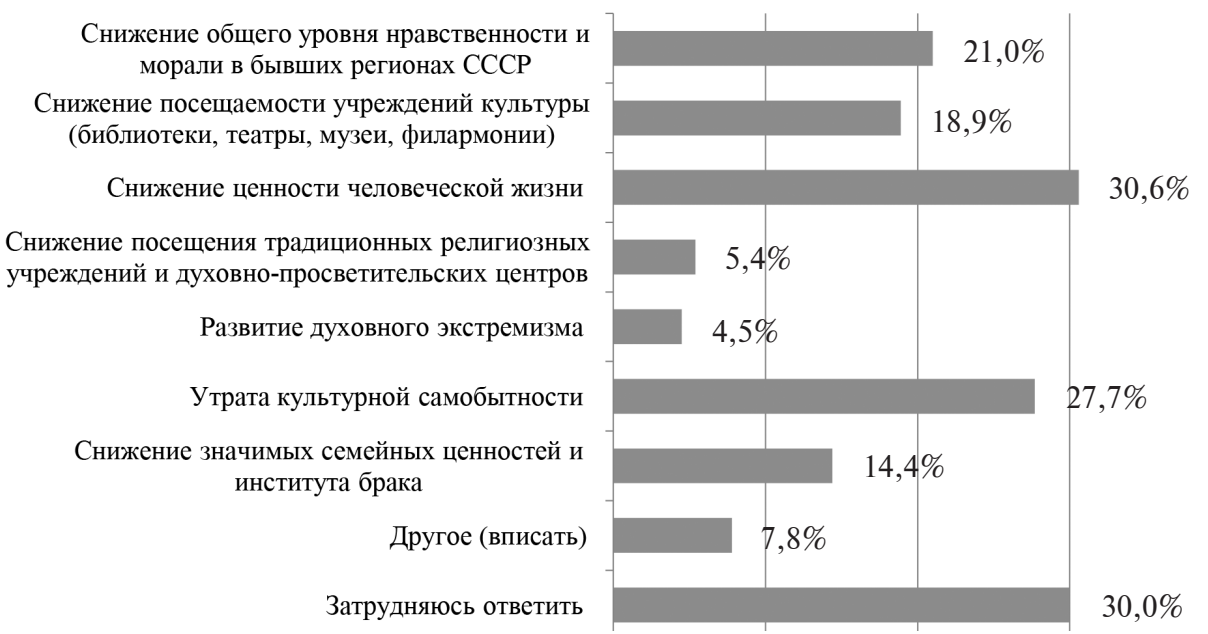

Рисунок 3. Распределение ответов на вопрос: «В чем, по Вашему мнению, выражается изменение в культурном поведении граждан приграничных регионов?» (Республика Карелия)

Наконец, совершенно особая специфика в характеристике культурного поведения была диагностирована в Республике Карелия. Во-первых, именно в данном регионе наибольшее число респондентов (30\%) вообще не смогли выделить какие-либо культурные изменения. Во-вторых, снижение общего уровня нравственности, которое наиболее часто отмечали жители других при- 
граничных регионов, в Карелии стало лишь четвертым по популярности вариантом ответа $(21,0 \%)$. В-третьих, именно в данном регионе участники опроса наиболее часто отмечали утрату культурной самобытности, свойственную населению приграничья.

Таблица 1

Глобальные социокультурные риски, наиболее актуальные для российского приграничья

\begin{tabular}{|c|l|c|}
\hline № & \multicolumn{1}{|c|}{ Вариант ответа } & Доля ответивших, \% \\
\hline 1. & Цифровизация & 17 \\
\hline 2. & Вестернизация & 20 \\
\hline 3. & Массовизация современной культуры & 3 \\
\hline 4. & Технологизация процесса культурного воспроизводства & 3 \\
\hline 5. & Виртуализация культуры & 24 \\
\hline 6. & Морально-нравственный кризис & 14 \\
\hline 7. & $\begin{array}{l}\text { Деформация каналов и механизмов трансляции } \\
\text { духовного наследия }\end{array}$ & \multicolumn{2}{|c|}{} \\
\hline
\end{tabular}

Значение глобальных социокультурных рисков может по-разному восприниматься различными социальными, в т.ч. возрастными, группами, что и имеет место на практике. Так, с возрастом респондентов повышается уровень консервативности в оценке морально-нравственного кризиса, вестернизации, а молодежь практически не учитывает угрозы цифровизации.

Социокультурный потенциал приграничных территорий не остается неизменным: он может развиваться (обогащаться) или, напротив, деградировать при повышении рисков и угроз. Траектория изменения зависит во многом от степени актуализации потенциала, его практического использования. Мощным интеграционным потенциалом обладает исторически сложившаяся особая модель гражданского общества, построенная с учетом групповых этнополитических, этнокультурных и этноконфессиональных интересов, что обеспечивает социокультурную безопасность [Авксентьев и др. 2019]. Тем не менее один и тот же элемент социокультурного потенциала может неоднозначно оцениваться субъектами приграничного взаимодействия по разные стороны границы. Неоднозначность проявлений социокультурного потенциала может быть связана с его реверсивностью, т.е. с возможностью как положительных, так и отрицательных проявлений. Социокультурный потенциал приграничных регионов не приводит автоматически к его реализации и зависит не только от рисков и угроз, но и от социально-технологического обеспечения развития приграничных регионов.

Таким образом, для приграничных регионов постсоветского пространства характерна высокая динамика рефлексивных образов трансформации социокультурного пространства. При этом основными объектами рефлексии становятся история взаимодействия, отражающая сегмент прошлого, состояние взаимоотношений населения приграничных регионов в настоящем, перспективы развития взаимоотношений в будущем.

Снижение социокультурных рисков и угроз может быть обеспечено путем применения комплекса социальных технологий, которые включают стратегический анализ, проектное управление, систему социальной диагностики и мониторинга, интернет-технологии. В этой связи органы власти приграничных регионов должны учитывать возможности проявления социокультур- 
ных угроз и рисков, обусловленных близостью государственной границы, что должно находить отражение в стратегических планах и прогнозах социальноэкономического развития территорий. Проведение такой политики будет способствовать предотвращению и преодолению негативных последствий, связанных с социально-культурными трансформациями приграничья.

\footnotetext{
Статья подготовлена при поддержке гранта Президента РФ для государственной поддержки молодых российских ученых - докторов наук в рамках проекта МД-578.2020.6 «Социокультурные угрозы трансформации иивилизационных фронтиров в постсоветском хронотопе».
}

\section{Список литературы}

Авксентьев В.А., Гриценко Г.Д., Иванова С.Ю., Шульга М.М. 2019. Интеграционный потенциал полиэтничного региона в контексте укрепления социокультурной безопасности. - Общество: социология, психология, педагогика. № 10(66). С. 14-21.

Игошева М.А. 2019. Этническая идентичность в условиях глобальных социокультурных рисков: угрозы и потенциал - Социально-гуманитарные знания. № 11. С. 25-31.

Нарыков Н.В., Скворцов И.П. 2020. Социокультурные аспекты национальной безопасности. - Философия права. № 3. С. 25-31.

Омельченко Д.А., Максимова С.Г., Ноянзина О.Е. 2021. Социальная безопасность региональных социумов российского приграничья: индивидуальные и институциональные факторы. - Society and Security Insights. T. 4. № 3. C.13-37.

Солихджонов Р., Джонназарова Д. 2013. Социокультурные противоречия в условиях глобализации общественной жизни - Вестник Таджикского государственного университета права, бизнеса и политики. № 2(54). С. 188-194.

Туркулец С.Е., Туркулец А.В., Листопадова Е.В. 2021. Влияние представлений о социальных угрозах и рисках на конструирование образа будущего России (опыт регионального исследования). - Социодинамика. № 1. С. 16-31.

Удаев Р.А. 2018. Безопасность и идентичность: этнокультурные аспекты. Вестник Калмыцкого государственного университета. № 4(40). С. 156-162.

\footnotetext{
SAPRYKA Viktor Aleksandrovich, Dr.Sci. (Soc.), Head of the Chair of Social Technologies and Public Service, Belgorod State National Research University (85 Pobedy St, Belgorod, Russia, 308015; sapryka@bsu.edu.ru)

KULAKOVA Natalya Igorevna, postgraduate student of the Chair of Social Technologies and Public Service, Belgorod State National Research University (85 Pobedy St, Belgorod, Russia, 308015)

SOLOKHA Valery Viktorovich, Applicant at the Chair of Social Technologies and Public Service, Belgorod State National Research University (85 Pobedy St, Belgorod, Russia, 308015)

OLEINIK Svetlana Anatolyevna, Applicant at the Chair of Social Technologies and Public Service, Belgorod State National Research University (85 Pobedy St, Belgorod, Russia, 308015)
}

\section{SOCIOCULTURAL RISKS AND THREATS TO THE DEVELOPMENT OF BORDER REGIONS}

\footnotetext{
Abstract. The article discusses the features of the development of border regions and highlights the socio-cultural risks and threats that arise in the border area. The study identifies trends for predicting possible vectors for the development of border regions and for making managerial decisions. The authors consider regional factors expressing the cultural and
} 
civilizational features of the border countries and the modern world development. The article focuses on the socio-cultural transformations in the Russian-Ukrainian, Russian-Belarusian and Russian-European border areas, which determine the features of the border development of the regions.

Keywords: sociocultural risks, threats, development, cultural and civilizational features, border regions

КЛИМАШЕВСКАЯ Ольга Викторовна - кандидат политических наук, доцент Московского авиационного института (национальный исследовательский университет) (125993, Россия, г. Москва, ГСП-3, Волоколамское ш., 4; Klimawevskaya@yandex.ru)

\section{ПРОБЛЕМЫ ДЕЙСТВУЮЩЕЙ СИСТЕМЫ И СТРУКТУРЫ ФЕДЕРАЛЬНЫХ ОРГАНОВ ИСПОЛНИТЕЛЬНОЙ ВЛАСТИ}

Аннотация. В статье рассматривается существующая система разделения функционала федеральных органов исполнительной власти, проблемы ее построения в рамках действующего законодательства. Проведенный анализ обосновывает необходимость реформирования существующей системы с учетом принципов целесообразности для эффективного исполнения государственных функций. Автор формулирует вывод, что совершенствование структуры федеральных органов исполнительной власти и разграничение функций между ними должно происходить на основе юридического механизма, позволяющего осуществлять три базовых правила нормотворческой деятельности.

Ключевые слова: система и структура федеральных органов исполнительной власти, указ Президента РФ, государственное управление, федеральные министерства, федеральные службы, федеральные агентства

$\Pi$ роблема эффективности институциональных структур исполнительной власти является актуальной для большинства современных государств, в т.ч. и для России. Реформирование, оптимизация систем исполнительной власти уже успели превратиться во многих из них в перманентную функцию государства. Упрощение административных функций, корректировка системы государственных органов и управления кадрами государственных служащих и другие масштабные мероприятия по модернизации государственного управления планомерно проводятся правительственными органами, специально созданными для этой цели.

В России с 1992 по 2005 г. вышли около 100 указов Президента РФ, меняющих систему и структуру федеральной исполнительной власти, что влекло за собой изменение функций, видов органов, их компетенций, форм и процедур реализации полномочий, штатов данных органов и т.д. Данная деятельность государственной власти не имела системного и последовательного характера.

Под административной реформой следует понимать совокупность мероприятий по совершенствованию организации, форм и методов деятельности исполнительной власти, реализуемых государством. В формировавшейся модели органов исполнительной власти стояла четкая задача разведения функционала между ними.

Так, федеральные министерства должны вырабатывать государственную политику и нормативно-правовое регулирование в установленной актами Президента РФ и Правительства РФ сфере деятельности; федеральные службы 